\title{
Artificial Neural Network Application for Contingency Ranking Based on Condition Number Incorporating IPFC
}

\author{
${ }^{* 1}$ Suresh Babu Daram, ${ }^{2}$ P.S.Venkataramu, ${ }^{3}$ M.S.Nagaraj \\ ${ }^{1}$ VTU, Belgaum, Karnataka, India \& Assistant Professor, Sree Vidyanikethan Engineering College, Tirupathi, \\ Andhra Pradesh, India, ${ }^{2}$ Director-IQAC, REVA University, Bangalore, Karnataka, India \\ ${ }^{3}$ Professor \& Head Department of Electrical and Electronics Engineering, Bapuji Institute of Engineering \& \\ Technology, Davangere, Karnataka, India \\ E-mail: *sureshbabudaram@gmail.com, venkataramu_ps@yahoo.com,
}

Received: $10^{\text {th }}$ December 2017, Accepted: 8th February 2018, Published: 28th February 2018

\begin{abstract}
This paper investigates the effect of incorporating an IPFC on Contingency Ranking(CR). The contingencies are ranked based Condition Number (CN) of the Jacobian matrix of Newton- Raphson load flow technique. The contingency ranking was done for single transmission line outage conditions with and without incorporating IPFC. Further, the ranking was done under system load enhancement condition. Suitable Artificial Neural Network (ANN) architectures are designed to predict the contingency ranking of a system. The results obtained based on case studies carried out on IEEE6 Bus System and Indian Utility UPSEB-75 Bus System are presented. MATLAB environment was used for simulation purpose.
\end{abstract}

\section{Keywords}

Contingency Ranking, FACTS, IPFC, Condition Number, ANN

\section{Introduction}

One of the major tasks of EMS is to carry out the contingency analysis. Steady state contingency analysis is carried out on real power systems for evaluating the performance of the system and to determine the necessary control actions. Generally it is not feasible and required to consider all the possible contingencies in the system for such study, hence credible contingencies are required to be ranked based on their relative severity. The study of contingency is an essential activity during power system planning, operation and control. So, power system security is one of the important concerns for power engineers to maintain the system stability for all kinds of outages. In some cases of contingency, the effects may lead to transmission line overloads or bus voltage limit violations. As the process of cascading outages in the system may lead to complete black out or collapse of the system. Static system results are very helpful to the system operators to secure the system during any transmission line outage in the system. To overcome such issues, there is a need to identify such contingencies. Contingency screening and ranking process accurately determines the possibility of specific contingencies which may cause power system instability based on their severity. Contingency selection is one such study which has the ability to identify the critical contingency in the system. Suitable preventive control actions can be implemented considering contingencies that are likely to affect the power system performance.

As the recent power systems are experiencing the threat of voltage instability, the contingencies are required to be ranked incorporating voltage stability phenomenon. The curve fitting approach has been proposed for contingency ranking in [1]. The change in the estimation of the loading margin to voltage collapse when a line outage occurs is compared by continuation power flow to obtain a nominal loading margin, and then linear quadratic sensitivities of the loading margin to each contingency are computed to find the resulting change in the loading margin [2]. The second order information derived from the Singular Value Decomposition (SVD) analysis of the load flow Jacobian matrix to obtain the contingency ranking [3]. A methodology for on-line voltage stability assessment for the voltage collapse point is determined through an extrapolation technique based on target vector behavior in [4]. A powerful procedure for identifying severe single branch outage contingency with respect to saddle node bifurcation induced voltage collapse, given an operating point, a load demand forecast and a generation dispatch [5]. The target vector where the idea consists of monitoring target vector norm associated with each contingency is given in [6]. The static voltage collapse indicator (LF-index) for the ranking of line outage contingency utilizing normal power flow calculations is developed. The maximum power transfer theory is used to calculate this indicator. The purpose of this indicator is to quantify the proximity of a particular operating point to voltage collapse [7]. The severity based on super components which refer to complex electrical facilities as: substations, generation plants and multiple circuit transmission lines. An outage of the super component implies the multiple and simultaneous outages of many elements. These kinds of events are not, generally, considered in the mentioned analyses; however, it would be very important to keep them in mind in the security evaluation of power systems [8]. The single line outage contingency ranking through condition 
number of the Jacobian matrix obtained from the Newton - Raphson load flow method is in [9].

A neural network based approach for contingency ranking using singular value decomposition (SVD) method using Radial Bias Function (RBF) neural network is trained to map the operating condition of power system to a voltage stability indicator and contingency severity indices corresponding to transmission lines [10]. An RBF network to capture the non-linear relationship between the precontingency system state and the post-contingency severity level and the input feature selection using the mutual information index are in [11]. A fuzzy neural model comprising of a screening and ranking model for on-line voltage contingency screening and a four-stage Multi-output parallel self-organizing hierarchical neural network has been used to serve as ranking module to rank screened critical contingencies. A performance index is used in this work, which combines the effect of voltage violation and voltage stability margin [12]. An approach based on RBF neural network to rank contingencies expected to cause steady state bus voltage solutions. Euclidean distance- based clustering technique is employed to select RBF parameters [13].

The Interline Power Flow Controller (IPFC) has shown a great extent in the family of Flexible AC Transmission Systems (FACTS) for having the capability of controlling multi-transmission lines at a time. The direct modeling of the practical series operating IPFC including inequality constraints and with low coupling-transformer impedances incorporated in the Jacobian element as the transformer less controller [15]. The combination of Tabu-Search (TS) algorithm and ANN to identify the suitable location to install IPFC and the validation with Levenberg-Marquardt back propagation and gradient decent is in [16]. A control scheme and gives the relationship between the series voltage injected by the UPFC/IPFC and the resulting power flow in the transmission line is analytically derived. Then, based on this relationship, two power flow control schemes are developed. One of the schemes relies on the priori knowledge of the line impedance angle, while the other scheme does not. Both schemes are applied to a transmission line with an IPFC [17].

\section{Interline Power Flow Controller (Ipfc)}

IPFC has the capability of controlling the active and reactive power of the first transmission line where it has incorporated and the reactive power of the second transmission line. The steady state model of IPFC developed to incorporate in NR load flow solution is considered from [18].

\section{Fig. 1 Conceptual hardware configuration of} IPFC

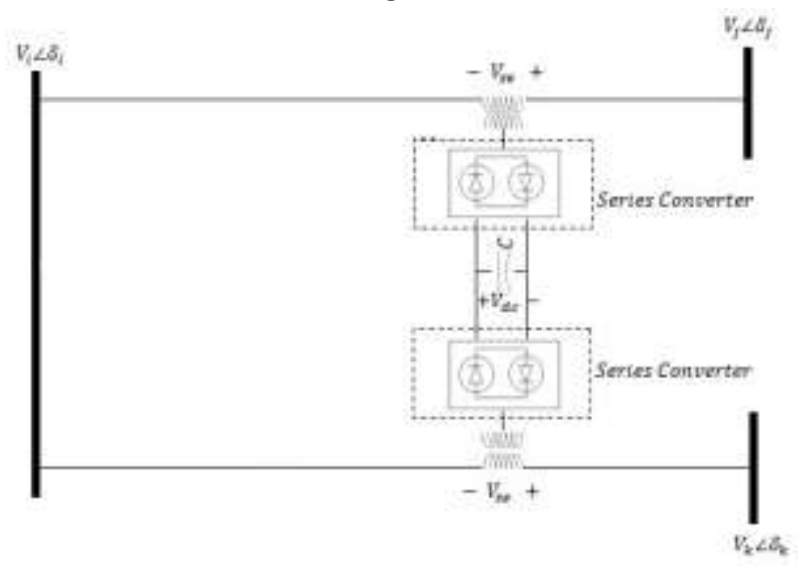

The Power Injection Model (PIM) of IPFC has been developed with the help of VSC by using two SSSCs. In this model the incorporation of the IPFC in power system is done without changing the size of the Jacobian elements for N-R method. The modeling is done depending on the impedance of series transformer connected in the transmission line.

The transformer is represented as a series reactance with the reactance of transmission line and with a series voltage source. $V_{i}^{\prime}$ is an imaginary voltage behind the reactance $X_{s e}$ is given in Eqn. (1).

$$
V_{i}^{\prime}=V_{s e}+V_{i}
$$

Series voltage $V_{s e}$ is controlled by both in magnitude and phase angle as in Eqn. (2).

$$
V_{s e i}=r V_{i} e^{i \gamma}
$$

Where $0 \leq r \leq r_{\max }$ and $-\pi \leq \gamma \leq \pi$

The power injected model can be obtained by replacing the voltage source $V_{s e}$ by a current source $I_{s e}$ in parallel with transmission line. The Power Injection Model (PIM) of IPFC with four control parameters has been developed. The power injection model has been derived from the Fig. 1.

Let the series connected voltage source converter between bus- $i$ to bus- $j$ is converter-I and between bus $\mathrm{i}$ to bus $\mathrm{k}$ is converter-II. The equivalent circuit diagram of Fig. 1 with a series connected VSC in the transmission lines $i-j \&$ $i-k$ is shown in Fig. 2. 
Fig. 2 Equivalent Circuit of IPFC

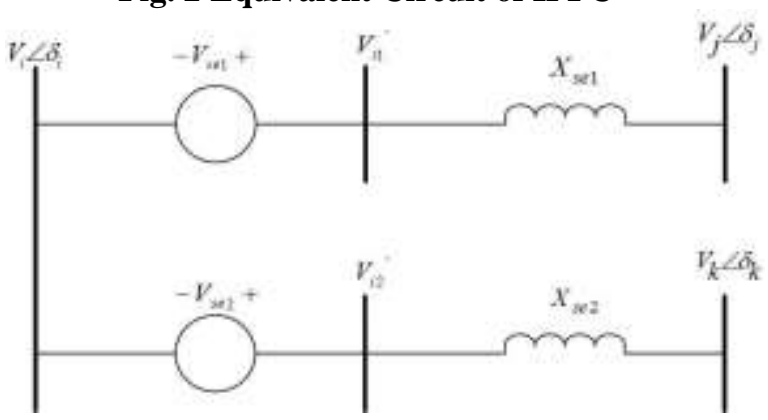

The transformer is represented as a reactance in series with the impedance of the transmission line and a voltage source. The two series converters are controlled separately by their individual parameters. The voltage of bus- $i$ is $V_{i}$ and is assumed to be reference vector as $V_{i}=V_{i} \angle 0$. Voltage of first series controller is controlled is $V_{\text {sel }}$. The magnitude and phase angle is given in Eqn. (3)

$$
V_{s e 1}=r_{1} \cdot V_{i} \cdot e^{j \gamma_{1}}
$$

An imaginary voltage behind the series reactance $X_{s e 1}$ is given below in Eqn. (4)

$$
V_{i 1}^{\prime}=V_{s e 1}+V_{i}
$$

Voltage of second series controller is controlled is $V_{s e 2}$. The magnitude and phase angle is given in Eqn. (5).

$$
V_{s e 2}=r_{2} \cdot V_{i} \cdot e^{j \gamma_{2}}
$$

Where $0 \leq r_{2} \leq r_{\max }$ and $-\pi \leq \gamma_{2} \leq \pi$.

An imaginary voltage behind the series reactance $X_{s e 2}$ is given below in Eqn. (6)

$$
V_{i 2}^{\prime}=V_{s e 2}+V_{i}
$$

The effect of current source $I_{s e 1} \& I_{s e 2}$ and susceptance $b_{s e 1} \& b_{s e 2}$ can be modeled by injected powers at buses $i, j \& k$. The current flowing in individual transmission lines are given in Eqn. (7) \& in Eqn. (8).

$$
\begin{aligned}
& I_{s e 1}=-j b_{s e 1} V_{s e 1} \\
& I_{s e 2}=-j b_{s e 2} V_{s e 2}
\end{aligned}
$$

The injected active and reactive power at bus $i$ is given in Eqn. (9) \& Eqn. (10)

$$
\begin{gathered}
P_{i, i n j}=-\left(r_{1} \cdot b_{s e 1} \cdot V_{i}^{2} \sin \gamma_{1}+r_{1} \cdot b_{s e 2} \cdot V_{i}^{2} \sin \gamma_{2}\right) \\
Q_{i, i n j}=-\left(r_{1} \cdot b_{s e 1} \cdot V_{i}^{2} \cos \gamma_{1}+r_{1} \cdot b_{s e 2} \cdot V_{i}^{2} \cos \gamma_{2}\right)
\end{gathered}
$$

The injected active and reactive power at bus $j$ is given in Eqn. (11) \& Eqn. (12)

$$
\begin{aligned}
& P_{j, i n j}=r_{1} \cdot b_{s e 1} \cdot V_{i} . . V_{j} \cdot \sin \left(\delta_{i}-\delta_{j}+\gamma_{1}\right) \\
& Q_{j, i n j}=r_{1} \cdot b_{s e 1} \cdot V_{i} . . V_{j} \cdot \cos \left(\delta_{i}-\delta_{j}+\gamma_{1}\right)
\end{aligned}
$$

The injected active and reactive power at bus $k$ is given in Eqn. (13) \& Eqn. (14)

$$
P_{k, i n j}=r_{2} \cdot b_{s e 2} \cdot V_{i} \cdot V_{k} \cdot \sin \left(\delta_{i}-\delta_{k}+\gamma_{2}\right)
$$

$$
Q_{k, i n j}=r_{2} \cdot b_{s e 2} \cdot V_{i} \cdot V_{k} \cdot \cos \left(\delta_{i}-\delta_{k}+\gamma_{2}\right)
$$

The Jacobian matrix can be modified using the above injected power from Eqn. (9) to Eqn. (14). By expanding the regular Newton Raphson method and neglecting all higher order terms, the set of linear expressions are shown in matrix form as given in Eqn. (15).

$\left[\begin{array}{cccccc}\frac{\partial P_{i}}{\partial \delta_{i}} & \frac{\partial P_{i}}{\partial \delta_{j}} & \frac{\partial P_{i}}{\partial \delta_{k}} & \frac{\partial P_{i}}{\partial V_{i}}+2 P_{i, n j} & \frac{\partial P_{i}}{\partial V_{j}} & \frac{\partial P_{i}}{\partial V_{k}} \\ \frac{\partial P_{j}}{\partial \delta_{i}}+Q_{j, i n j} & \frac{\partial P_{j}}{\partial \delta_{j}}-Q_{j, i n j} & \frac{\partial P_{j}}{\partial \delta_{i}} & \frac{\partial P_{j}}{\partial V_{i}}+P_{j, i n j} & \frac{\partial P_{j}}{\partial V_{j}}+P_{j, i n j} & \frac{\partial P_{j}}{\partial V_{k}} \\ \frac{\partial P_{k}}{\partial \delta_{i}}+Q_{k, i n j} & \frac{\partial P_{k}}{\partial \delta_{j}} & \frac{\partial P_{k}}{\partial \delta_{i}}-Q_{k, i n j} & \frac{\partial P_{k}}{\partial V_{i}}+P_{k, i n j} & \frac{\partial P_{k}}{\partial V_{j}} & \frac{\partial P_{k}}{\partial V_{k}}+P_{k, i n j} \\ \frac{\partial Q_{i}}{\partial \delta_{i}} & \frac{\partial Q_{i}}{\partial \delta_{j}} & \frac{\partial Q_{i}}{\partial \delta_{i}} & \frac{\partial Q_{i}}{\partial V_{i}}+2 Q_{i, n j} & \frac{\partial Q_{i}}{\partial V_{j}} & \frac{\partial Q_{i}}{\partial V_{k}} \\ \frac{\partial Q_{j}}{\partial \delta_{i}}-P_{j, i n j} & \frac{\partial Q_{j}}{\partial \delta_{j}}+P_{j, i n j} & \frac{\partial Q_{j}}{\partial \delta_{i}} & \frac{\partial Q_{j}}{\partial V_{i}}+Q_{j, i n j} & \frac{\partial Q_{j}}{\partial V_{j}}+Q_{j, i n j} & \frac{\partial Q_{j}}{\partial V_{k}} \\ \frac{\partial Q_{k}}{\partial \delta_{i}}-P_{k, i n j} & \frac{\partial Q_{k}}{\partial \delta_{j}} & \frac{\partial Q_{k}}{\partial \delta_{i}}+P_{k, i n j} & \frac{\partial Q_{k}}{\partial V_{i}}+Q_{k, i n j} & \frac{\partial Q_{k}}{\partial V_{j}} & \frac{\partial Q_{k}}{\partial V_{k}}+Q_{k, i n j}\end{array}\right]$

\section{Contingency Ranking Methodology}

Condition Number (CN) computed for a NewtonRaphson (N-R) Jacobian matrix provides the severity of a line outage from the system stability point of view. The formulation of a problem is defined to be ill-conditioned if computed values are very sensitive to small changes in input values. The Condition Number $(\mathrm{CN})$ is an analytical tool used in the linear system problem. A simple linear expression is given in Eqn. (16).

$$
A x=b
$$

Where, $A \in R^{\left(n^{*} n\right)}, b \in R^{\left(n^{*} n\right)}$.

The goal of the analysis is to examine how perturbation in the ' $A$ ' and ' $b$ ' matrices affects the solution $x$. Applying Singular Value Decomposition (SVD) to matrix 'A', Eqn. (17) is obtained.

$$
A=U \sum V^{T}=\sum_{i=1}^{u} \sigma_{i} u_{i} V_{i}^{T}
$$

Therefore, the solution to ' $x$ ' is given in Eqn. (18).

$$
x=A^{-1} b=\sum_{i=1}^{u} \frac{u_{i}^{T} b V_{i}}{\sigma_{i}}
$$

From Eqn. (18) it is seen that a small change in either ' $A$ ' or ' $b$ ' may cause large changes in ' $x$ ' if $\sigma_{\min }$ is small enough. A precise measure of the sensitivity of the linear system is needed in order to determine stability when disturbed. This concept is applied to find the condition number of the N-R load flow Jacobian (J) as in Eqn. (19) or Eqn. (20).

$$
\begin{aligned}
& C N(J)=\frac{\sigma_{\max }(J)}{\sigma_{\min }(J)} \\
& C N(J)=\|J\|\left\|J^{-1}\right\|
\end{aligned}
$$


The value of $C N(J)$ gives an indication of the condition of "J" "with respect to inversion". A small value of $C N(J)$ refers to what is called a wellconditioned matrix, one that is not very sensitive to perturbation. On the other hand, if a matrix is highly sensitive to perturbation it is said to be illconditioned and is characterized by a very large value of $C N(J)$. This condition number is used to measure the nearness to the singularity of the Jacobian of the load flow, since $\sigma_{\text {min }}=0$, at voltage collapse, $C N(J)$ will be equal to infinity at that point.

\section{Contingency Screening}

A.C load flow is carried out on the selected system for base case load and pre-contingency conditions. Theoretically for ' $L$ ' number of transmission lines in the system there will be ' $L$ ' number of single transmission line outage contingencies and many double transmission line outage contingencies. It is not necessary to carry out contingency ranking for all the line outages and hence the lines to be considered for ranking are selected based on the following criterions:

i. All the heavily loaded lines

ii. Lines connected to such buses whose (any one) voltage is less than the minimum limit.

\section{Proposed Algorithm}

Condition number is basically computed as one indicator to the whole system for a given operating condition.

Step-1: The Condition number $C N(J)$ of the converged load flow Jacobian for the base case and at the pre contingency case is computed.

Step-2: The selected contingency one at a time is imposed on the system and $C N(J)$ is computed.

Step-3: Contingencies are ranked in the decreasing order of condition number (i.e., the lower value of the condition number indicates the less severe contingency)

Step-4: All steps are repeated for different loading condition

\section{Case Study and Results}

In this section, numerical results are carried out on IEEE 6-bus system, IEEE 14-bus system and IEEE 30-bus system to show the robustness of the proposed methodology [19].

\section{IEEE-6 Bus System}

This system consists of a slack bus, 2 generator buses, 3 load buses and 11 transmission lines As the system is small, all the single line outage contingencies are considered as given in Table 1

Table 1: List of Single Line Outage Contingencies in IEEE-6 Bus System

\begin{tabular}{|c|c|c|c||c|c|c|c|}
\hline $\begin{array}{c}\text { Contingency } \\
\text { No. }\end{array}$ & $\begin{array}{c}\text { Line } \\
\text { No. }\end{array}$ & $\begin{array}{c}\text { From } \\
\text { Bus }\end{array}$ & $\begin{array}{c}\text { To } \\
\text { Bus }\end{array}$ \\
\hline 1 & 1 & 1 & 2 \\
\hline 2 & 2 & 1 & 4 & $\begin{array}{c}\text { Contingency } \\
\text { No. }\end{array}$ & $\begin{array}{c}\text { Line } \\
\text { No. }\end{array}$ & $\begin{array}{c}\text { From } \\
\text { Bus }\end{array}$ & $\begin{array}{c}\text { To } \\
\text { Bus }\end{array}$ \\
\hline 3 & 3 & 1 & 5 & 5 & 5 & 2 & 4 \\
\hline 4 & 4 & 2 & 3 & 6 & 6 & 2 & 5 \\
\hline & & & 7 & 7 & 2 & 6 \\
\hline
\end{tabular}

Table 2: Contingency Ranking based on CN for IEEE-6 Bus System

\begin{tabular}{|c|c|c|c|c|c|c|c|c|}
\hline \multirow{3}{*}{ Rank } & \multirow{2}{*}{\multicolumn{2}{|c|}{$\begin{array}{c}100 \% \\
\text { System load } \\
\text { Line No./ } \\
\text { Condition No. }\end{array}$}} & \multirow{2}{*}{\multicolumn{2}{|c|}{$\begin{array}{c}120 \% \\
\text { System load } \\
\text { Line No./ } \\
\text { Condition No. }\end{array}$}} & \multirow{2}{*}{\multicolumn{2}{|c|}{$\begin{array}{c}140 \% \\
\text { System load } \\
\text { Line No./ } \\
\text { Condition No. }\end{array}$}} & \multirow{2}{*}{\multicolumn{2}{|c|}{$\begin{array}{c}160 \% \\
\text { System load } \\
\text { Line No./ } \\
\text { Condition No. }\end{array}$}} \\
\hline & & & & & & & & \\
\hline & $\mathrm{IPFC}_{0}$ & $\mathrm{IPFC}_{1}$ & $\mathrm{IPFC}_{0}$ & $\mathrm{IPFC}_{1}$ & $\mathrm{IPFC}_{0}$ & $\mathrm{IPFC}_{1}$ & $\mathrm{IPFC}_{0}$ & $\mathrm{IPFC}_{1}$ \\
\hline I & $\begin{array}{c}2 / \\
24.3043 \\
\end{array}$ & $\begin{array}{c}2 / \\
24.2627\end{array}$ & $\begin{array}{c}3 / \\
25.2658 \\
\end{array}$ & $\begin{array}{c}3 / \\
24.5276 \\
\end{array}$ & $\begin{array}{c}2 / \\
26.8087 \\
\end{array}$ & $\begin{array}{c}3 / \\
25.4308 \\
\end{array}$ & $\begin{array}{c}2 / \\
29.2255 \\
\end{array}$ & $\begin{array}{c}3 / \\
26.7479 \\
\end{array}$ \\
\hline III & $\begin{array}{c}1 / \\
23.8239 \\
\end{array}$ & $\begin{array}{c}3 / \\
23.3271 \\
\end{array}$ & $\begin{array}{c}1 / \\
24.6499\end{array}$ & $\begin{array}{c}1 / \\
23.6003\end{array}$ & $\begin{array}{c}1 / \\
26.3019 \\
\end{array}$ & $\begin{array}{c}1 / \\
24.7369\end{array}$ & $\begin{array}{c}3 / \\
28.2258 \\
\end{array}$ & $\begin{array}{c}1 / \\
26.6252 \\
\end{array}$ \\
\hline IV & $\begin{array}{c}7 / \\
16.9284\end{array}$ & $\begin{array}{c}7 / \\
16.8664\end{array}$ & $\begin{array}{c}7 / \\
17.2554\end{array}$ & $\begin{array}{c}7 / \\
16.9067\end{array}$ & $\begin{array}{c}7 / \\
17.8512 \\
\end{array}$ & $\begin{array}{c}7 / \\
17.3493\end{array}$ & $\begin{array}{c}9 / \\
19.9624\end{array}$ & $\begin{array}{c}9 / \\
19.5356\end{array}$ \\
\hline V & $\begin{array}{c}4 / \\
16.8477 \\
\end{array}$ & $\begin{array}{c}4 / \\
16.7048 \\
\end{array}$ & $\begin{array}{c}4 / \\
17.2385 \\
\end{array}$ & $\begin{array}{c}4 / \\
16.8011 \\
\end{array}$ & $\begin{array}{c}4 / \\
17.7619 \\
\end{array}$ & $\begin{array}{c}4 / \\
17.1422 \\
\end{array}$ & $\begin{array}{c}5 / \\
18.6636 \\
\end{array}$ & $\begin{array}{c}7 / \\
17.9636 \\
\end{array}$ \\
\hline VIII & $\begin{array}{c}5 / \\
15.5140\end{array}$ & $\begin{array}{c}6 / \\
15.3383\end{array}$ & $\begin{array}{c}6 / \\
15.6246\end{array}$ & $\begin{array}{c}6 / \\
15.0378\end{array}$ & $\begin{array}{c}6 / \\
16.1579\end{array}$ & $\begin{array}{c}6 / \\
15.3578\end{array}$ & $\begin{array}{c}6 / \\
16.8968\end{array}$ & $\begin{array}{c}6 / \\
15.8429\end{array}$ \\
\hline
\end{tabular}


Initially, the load flow solution without contingency was carried out for obtaining condition number of the Jacobian matrix. The condition number is obtained under contingencies mentioned in Table 1 for different loading condition. From Table 2 it can be observed that the condition number increases with the increment in the system load. The values of condition number have been reduced with IPFC compared to without IPFC in the system. For IEEE6 bus system line number 2 is having the highest value of Condition number with and without IPFC in the system. In some cases line number 3 is having the next highest value.

\section{Indian Utility UPSEB-75 Bus System}

This system consists of 1-slack bus, 14-generator buses, 60-load buses and 98-transmission lines. On contingency screening total 17-transmission line outage contingencies are considered for ranking. The line outages considered for ranking is listed in Table 3. Condition number is obtained under contingencies mentioned in Table 4 under base case loading condition and system load enhancement. Similar study as mentioned in Table 2 is considered for ranking the transmission line outage contingency and the transmission line numbers are given in Table 4. From Table 4 it can be observed that the condition number increases with the increment in the system load. The rank of the transmission line has slightly changed for almost all the transmission lines. In UPSEB-75bus system line number 67 is having the highest value of Condition number with and without IPFC in the system. In some cases line number 28 and 31 is having the next highest value.

Table 3: List of Single Line Outage Contingencies in UPSEB 75-Bus system

\begin{tabular}{|c|c|c|c||c|c|c|c|}
\hline $\begin{array}{c}\text { Contingency } \\
\text { No. }\end{array}$ & $\begin{array}{c}\text { Line } \\
\text { No. }\end{array}$ & $\begin{array}{c}\text { From } \\
\text { Bus }\end{array}$ & $\begin{array}{c}\text { To } \\
\text { Bus }\end{array}$ & $\begin{array}{c}\text { Contingency } \\
\text { No. }\end{array}$ & $\begin{array}{c}\text { Line } \\
\text { No. }\end{array}$ & $\begin{array}{c}\text { From } \\
\text { Bus }\end{array}$ & $\begin{array}{c}\text { To } \\
\text { Bus }\end{array}$ \\
\hline 1 & 26 & 16 & 50 & 10 & 67 & 74 & 73 \\
\hline 2 & 28 & 17 & 23 & 11 & 69 & 29 & 22 \\
\hline 3 & 31 & 19 & 26 & 12 & 70 & 26 & 41 \\
\hline 4 & 34 & 24 & 27 & 13 & 71 & 48 & 49 \\
\hline 5 & 42 & 28 & 43 & 14 & 74 & 38 & 22 \\
\hline 6 & 44 & 56 & 30 & 15 & 76 & 30 & 65 \\
\hline 7 & 49 & 57 & 58 & 16 & 88 & 43 & 56 \\
\hline 8 & 59 & 35 & 36 & 17 & 95 & 21 & 30 \\
\hline 9 & 64 & 40 & 48 & & - & & \\
\hline
\end{tabular}

Table 4: Contingency Ranking based on CN for UPSEB 75-bus system

\begin{tabular}{|c|c|c|c|c|c|c|c|c|}
\hline \multirow{3}{*}{ Rank } & \multicolumn{2}{|c|}{$\begin{array}{c}100 \% \\
\text { System load }\end{array}$} & \multicolumn{2}{c|}{$\begin{array}{c}120 \% \\
\text { System load }\end{array}$} & \multicolumn{2}{c|}{$\begin{array}{c}140 \% \\
\text { System load }\end{array}$} & \multicolumn{2}{c|}{$\begin{array}{c}160 \% \\
\text { System load }\end{array}$} \\
\cline { 2 - 9 } & \multicolumn{2}{|c|}{ Line No. } & \multicolumn{2}{c|}{ Line No. } & \multicolumn{2}{c|}{ Line No. } & \multicolumn{2}{c|}{ Line No. } \\
\cline { 2 - 9 } & IPFC $_{0}$ & IPFC $_{1}$ & IPFC $_{0}$ & IPFC $_{1}$ & IPFC $_{0}$ & IPFC $_{1}$ & IPFC $_{0}$ & IPFC $_{1}$ \\
\hline I & 67 & 67 & 67 & 67 & 67 & 67 & 67 & 67 \\
\hline II & 28 & 28 & 31 & 31 & 28 & 28 & 28 & 28 \\
\hline III & 64 & 76 & 28 & 28 & 64 & 26 & 64 & 49 \\
\hline IV & 34 & 34 & 70 & 88 & 34 & 34 & 34 & 34 \\
\hline V & 88 & 88 & 26 & 26 & 88 & 88 & 88 & 64 \\
\hline VI & 26 & 64 & 74 & 74 & 26 & 95 & 26 & 26 \\
\hline VII & 69 & 69 & 59 & 59 & 69 & 69 & 69 & 69 \\
\hline VIII & 31 & 31 & 88 & 64 & 31 & 31 & 31 & 88 \\
\hline IX & 95 & 95 & 42 & 42 & 95 & 74 & 95 & 95 \\
\hline X & 76 & 59 & 69 & 69 & 76 & 76 & 76 & 76 \\
\hline
\end{tabular}


Design of ANN Architecture for Prediction of $\mathrm{CN}$ for IEEE 6-Bus System

There are 25 input variables consisting of 6 bus voltage, one reactive power reserve and one reactive power loss 11 for depicting the line outage cases and 6 IPFC parameters. If IPFC is not considered 19 input variables are considered. 19 \& 25 input variables are considered for input layer and the ANN architecture is designed for predicting the output i.e., $\mathrm{CN}$. To choose the best architecture for the given problem a number of trial and error simulations were carried out and finally it was found that an input layer with 19 neurons, 2 hidden layers with 19 and 10 neurons and an output layer with one neuron was found to give best performance. The network is trained with back propagation algorithm considering 175 training patterns and the network is tested for another 25 patterns. Based on the designed architecture, the training process took 0.03 seconds for CPU time. The ANN architecture of the ANN is given in Table 5. All the simulations are carried out using MATLAB software in the i3 processor system with a clock speed of $2.18 \mathrm{GHz}$.

Table 5: ANN Architecture for IEEE-6 bus system of $\mathrm{CN}$

\begin{tabular}{|l|l|l|}
\hline Type of ANN Parameter & $\begin{array}{l}\text { Without } \\
\text { IPFC }\end{array}$ & $\begin{array}{l}\text { With } \\
\text { IPFC }\end{array}$ \\
\hline Number of input neurons & 19 & 25 \\
\hline Number of hidden layers & 2 & 2 \\
\hline $\begin{array}{l}\text { Number of neurons in } \\
\text { hidden layers }\end{array}$ & 19,10 & 25,10 \\
\hline Number of output neurons & 1 & 1 \\
\hline Error goal & 0.0001 & 0.0001 \\
\hline Learning rate & 0.4 & 0.4 \\
\hline $\begin{array}{l}\text { Minimum performance } \\
\text { gradient }\end{array}$ & $1 \mathrm{e}-7$ & $1 \mathrm{e}-7$ \\
\hline $\begin{array}{l}\text { Maximum number of } \\
\text { epochs }\end{array}$ & 50 & 50 \\
\hline
\end{tabular}

The performance characteristic of the ANN with and without IPFC is shown in Fig. 3 and Fig. 4 which gives the generalization capacity of the designed network. The performance of the ANN was test evaluated using 25 testing sets, which are different from the training set. This is essential to conform that the ANN acquires useful knowledge and does not just memorizes the training set.
The Table 6 gives the contingency ranking based on the predicted CNs for $150 \%$ load conditions along with the error in the predicted $\mathrm{CN}$ with and without IPFC in the system.

Fig. 3 Performance of ANN for CN for IEEE-6 bus system without IPFC

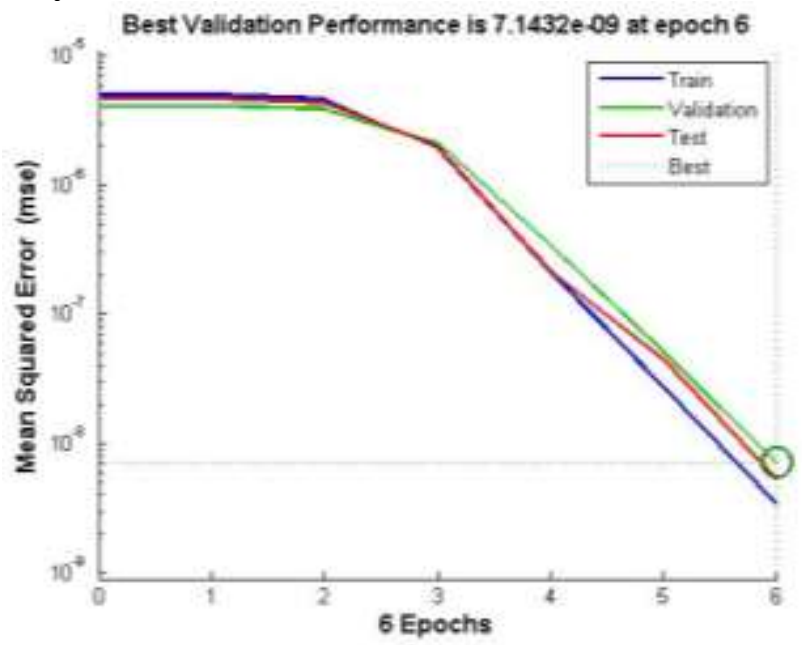

Fig. 4 Performance of ANN for CN for IEEE-6 bus system with IPFC

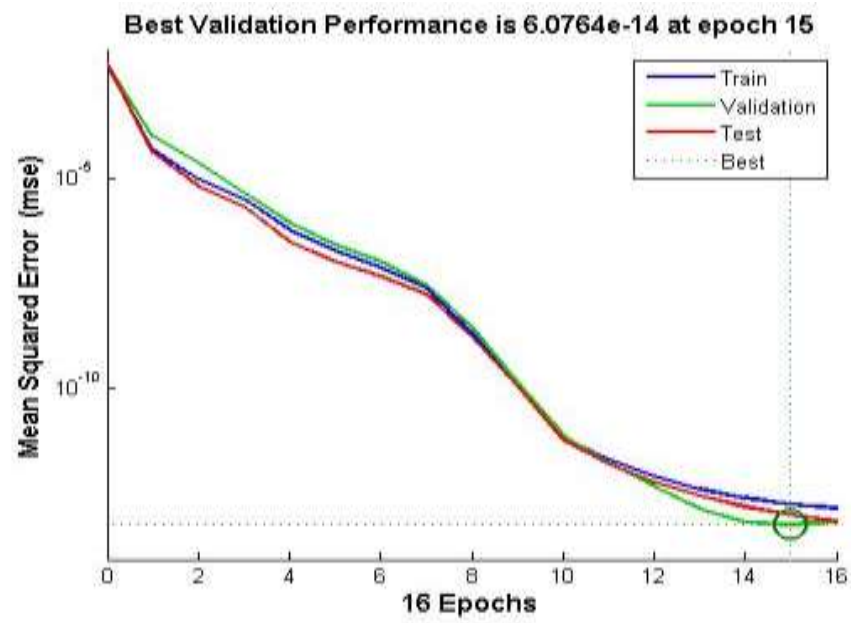

Table 6 Contingency Ranking based predicted CNs for IEEE-6 bus system

\begin{tabular}{|c|c|c|c|c|c|c|c|c|}
\hline \multirow{3}{*}{ Rank } & \multicolumn{9}{|c|}{ Without IPFC } & \multicolumn{4}{c|}{ With IPFC } \\
\cline { 2 - 9 } & \multicolumn{9}{|c|}{$\begin{array}{c}\text { Cont } \\
\text { No. }\end{array}$} & Target & Predicted & Error & $\begin{array}{c}\text { Cont } \\
\text { No. }\end{array}$ & Target & Predicted & Error \\
\hline I & 2 & 27.85981 & 27.8595998 & 0.000210 & 3 & 26.0615 & 26.061362 & 0.000138 \\
\hline II & 3 & 27.60027 & 27.6000478 & 0.000222 & 2 & 25.5792 & 25.578992 & 0.000158 \\
\hline III & 1 & 27.54919 & 27.5489406 & 0.000249 & 1 & 25.4851 & 25.484983 & 0.000157 \\
\hline IV & 7 & 18.95312 & 18.953056 & 0.000064 & 7 & 17.5413 & 17.54125 & 0.000050 \\
\hline V & 4 & 18.08146 & 18.0815239 & -0.000064 & 4 & 17.1421 & 17.142048 & 0.000062 \\
\hline VI & 9 & 17.99483 & 17.9947668 & 0.000063 & 9 & 17.19 & 17.189952 & 0.000068 \\
\hline VII & 5 & 17.99772 & 17.9978971 & -0.000177 & 5 & 16.9703 & 16.970233 & 0.000067 \\
\hline VIII & 6 & 16.66739 & 16.6676451 & -0.000255 & 6 & 15.6128 & 15.6127 & 0.000080 \\
\hline
\end{tabular}


Design of ANN Architecture for Prediction of $\mathrm{CN}$ for Indian Utility UPSEB-75 Bus System

In this case as the system is large and the input sets are more ( 75 bus voltages, 7 reactive power limits, 1 reactive power loss, 91 transmission lines , 6 IPFC parameters ) total 180 input variables are required. If IPFC is not considered total 174 input variables are required. So, these input variables are used for predicting the output i.e., $\mathrm{CN}$.

To choose the best architecture for the given problem a number of trial and error simulations were carried out and finally it was found without incorporating IPFC in the system, an input layer with 180 neurons, 2 hidden layers with 12 and 5 neurons and an output layer with one neuron was found to give best performance. If the IPFC is incorporated in the system, an input layer with 81 neurons, 2 hidden layers with 20 and 15 neurons and an output layer with one neuron was found to give best performance. The network is trained with back propagation algorithm considering 175 training patterns and the network is tested for another 25 patterns. Based on the designed architecture, the training process took 0.05 seconds for CPU time. The ANN architecture of the ANN is given in Table-VII. All the simulations are carried out using MATLAB software in the i3 processor system with a clock speed of $2.18 \mathrm{GHz}$.

Table 7 ANN Architecture for Indian Utility UPSEB-75 Bus System

\begin{tabular}{|l|l|l|}
\hline \multicolumn{1}{|c|}{ Type of ANN Parameter } & \multicolumn{1}{|c|}{$\begin{array}{c}\text { Without } \\
\text { IPFC }\end{array}$} & \multicolumn{1}{|c|}{$\begin{array}{c}\text { With } \\
\text { IPFC }\end{array}$} \\
\hline Number of input neurons & 174 & 180 \\
\hline Number of hidden layers & 2 & 2 \\
\hline $\begin{array}{l}\text { Number of neurons in hidden } \\
\text { layers }\end{array}$ & 29,12 & 30,12 \\
\hline Number of output neurons & 1 & 1 \\
\hline Error goal & 0.000155 & 0.000155 \\
\hline Learning rate & 0.435 & 0.435 \\
\hline $\begin{array}{l}\text { Minimum performance } \\
\text { gradient }\end{array}$ & $1 \mathrm{e}-7$ & $1 \mathrm{e}-7$ \\
\hline Maximum number of epochs & 50 & 50 \\
\hline
\end{tabular}

The performance characteristic of the ANN is shown in Fig 4.5 and Fig 4.6 which gives the generalization capacity of the designed network. The performance of the ANN was test evaluated using 25 testing sets, which are different from the training set. This is essential to conform that the ANN acquires useful knowledge and does not just memorizes the training set. The Table 8 gives the contingency ranking based on the predicted CNs for $150 \%$ load condition along with the error in the predicted $\mathrm{CN}$.

Fig. 5 Performance of ANN for CN for Indian Utility UPSEB-75 bus system without IPFC

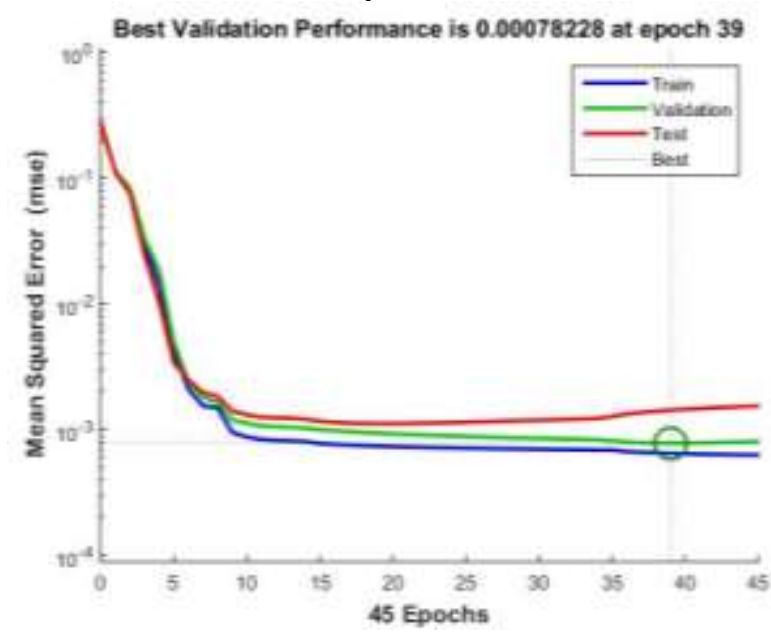

Fig. 6 Performance of ANN for CN for Indian Utility UPSEB-75 bus system with IPFC

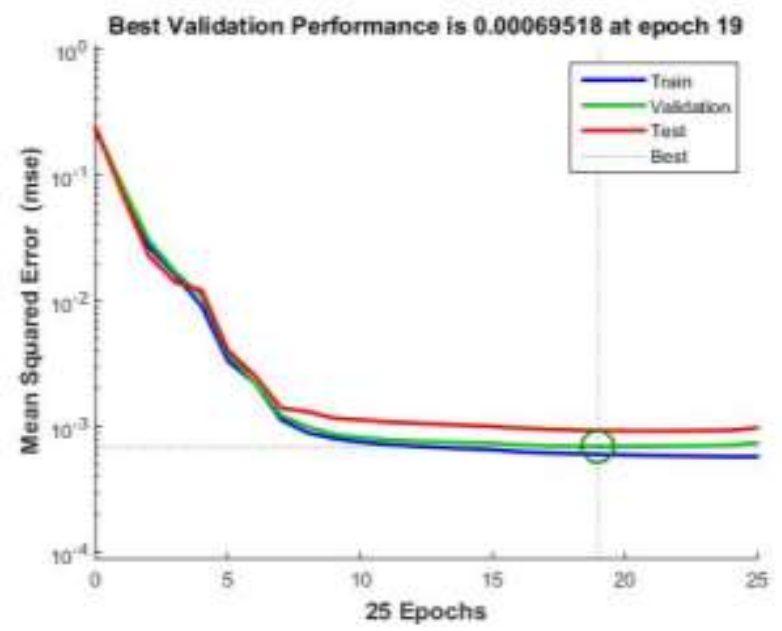


Helix Vol. 8(2): 3303-3312

Table 8 Contingency Ranking based predicted CNs for Indian Utility UPSEB-75 bus system

\begin{tabular}{|c|c|c|c|c|c|c|c|c|}
\hline \multirow{2}{*}{ Rank } & \multicolumn{9}{|c|}{$150 \%$ System Loading } \\
\cline { 2 - 9 } & \multicolumn{9}{|c|}{$\begin{array}{c}\text { Cont } \\
\text { No. }\end{array}$} & Target & Predicted & error & $\begin{array}{c}\text { Cont } \\
\text { No. }\end{array}$ & Target & Predicted & error \\
\hline I & 67 & 664.79891 & 664.79880 & -0.00010922 & 67 & 643.74568 & 643.74452 & -0.00115 \\
\hline II & 28 & 609.91466 & 609.91391 & -0.00074590 & 28 & 598.22342 & 598.22294 & -0.00049 \\
\hline III & 64 & 598.95722 & 598.95647 & -0.00074594 & 26 & 595.67551 & 595.67517 & 0.00034 \\
\hline IV & 34 & 542.78555 & 542.78480 & -0.00074594 & 34 & 529.39010 & 529.38973 & -0.00037 \\
\hline V & 88 & 540.02490 & 540.02415 & -0.00074594 & 88 & 525.38433 & 525.38394 & -0.00039 \\
\hline VI & 26 & 538.71617 & 538.71575 & 0.00041567 & 95 & 523.99030 & 523.98898 & 0.00133 \\
\hline VII & 69 & 531.84105 & 531.84030 & -0.00074594 & 69 & 519.33199 & 519.33153 & 0.00046 \\
\hline VIII & 31 & 526.65118 & 526.65067 & 0.00050905 & 31 & 514.50487 & 514.50395 & -0.00093 \\
\hline IX & 95 & 524.78852 & 524.78659 & -0.00193300 & 74 & 512.49909 & 512.49888 & -0.00021 \\
\hline X & 76 & 518.91988 & 518.91913 & -0.00074594 & 76 & 511.46944 & 511.46914 & 0.00030 \\
\hline
\end{tabular}

It is clear from the results that the designed ANN architecture is accurate in predicting CNs and once trained off-line it can predict $\mathrm{CN}$ for any unseen patterns accurately and hence has a great potential to use it in EMS on-line module.

\section{Conclusion}

The effect of installing a multi-transmission FACTS controller, i.e., IPFC in the system under single line outage conditions has been presented in this chapter. The proposed model of IPFC has been incorporated to understand the system under line outage condition. The system stability based on condition number $(\mathrm{CN})$ without IPFC is compared with IPFC. Further, ANN architectures are developed for accurate for on-line prediction of contingency ranking indices without and with incorporation of IPFC in the system. The results show a very good potential for incorporation of these architectures into the online security assessment modules in EMS.

\section{Acknowledgement}

The authors are grateful to the management of the Sree Vidyanikethan Engineering College, Tirupati and also to the management of Bapuji Institute of Engineering and Technology, Davangere.

\section{References}

[1] G. C. Ejebe, G. D. Irisarri, S. Mokhtari, O. Obadina, P. Ristanovic and J. Tong, "Methods for contingency screening and ranking for voltage stability analysis of power systems", IEEE Transactions on power systems, Vol. 11, No. 1, Feb. 1996, pp. 350-356.

[2] Scott Greene, Ian Dobson, Fernando L. Alvarado, 'Contingency ranking for voltage collapse via sensitivities from a single nose curve', IEEE Trans. On Power Systems, Vol.14, No.1, Feb 1999, pp 232-239.
[3] Alberto Berizzi, Yong-Gang Zeny, Paolo Marannno, Alsesandro Vaccarini, Pierangela A.Scarpellini, 'A Second Order method for Contingency severity assessment with respect to voltage collapse', IEEE Trans. On Power Systems, Vol.15, No.1, Feb 2000, pp 81-87.

[4] Antonio C.Zambroni de Souza, Julio C. Stachhini de Souza, Armando M. Leite de Silva,'Online Voltage stability monitoring', IEEE Trans. On Power Systems, Vol.15, No.4, Nov 2000, pp 1300-1305.

[5] Alexender.J.Fluek, Renuka Gonella, Jayabharath R. Dondeti, 'A new power sensitivity method of ranking branch outage contingencies for voltage collapse', IEEE Trans. On Power Systems, Vol.17, No.2, May 2002, pp 265-270.

[6] Acozambroni de Souza.A.C, Alves da silva.A.P, Jorge L.A,Jardim, SilvaNeto.C.A Torres.G.L, Claudio Ferrerira, Araiyo Ferreira.L.C,' A new Contingency analysis approach for voltage collapse assessment', International Journal on Electric Power and Energy Systems, Vol. 25, Jan 2003, pp 781-785.

[7] P. S. Venkataramu, "Power System Studies incorporating Voltage Collapse Phenomenon", a $\mathrm{PhD}$ thesis, Visvesvaraya Technological University, India, 2006.

[8] M. A. Caro, M. A. Ríos, "Super Components Contingency Modeling for Security Assessment in Power Systems", IEEE Latin America Transactions, Vol. 7, No. 5, September 2009, pp 552-559.

[9] Suresh Babu Daram, P. S. Venkataramu, M. S. Nagaraj, "Condition Number Based Contingency Ranking under Line Outage Condition Incorporating IPFC", International Conference on Renewable Energy Utilization, Dept. of EEE, Coimbatore Institute of Technology, Coimbatore, India, January 2016. 
[10] Wan.H.B, Ekwue.A.O, "Artificial neural network based contingency ranking method for voltage collapse", International Journal on Electric Power and Energy Systems, Vol.22, 2000, pp 349-354.

[11] Devaraj.D, Yegnanarayana.B, Ramar.K, "Radial basis function networks for fast contingency ranking", International Journal on Electric Power and Energy Systems, Vol.24, 2002, pp 387-395

[12] Manjaree Pandit, Laxmi Srivastava, Jaydev Sharma, "Fast voltage contingency selection using fuzzy parallel self-organizing hierarchical neural network", IEEE Trans. On Power Systems, Vol.18, No.2, May 2003, pp 657-664.

[13] Jain.T, Srivastava..L, Singh.S.N, "Fast contingency screening using radial basis function neural network", IEEE Trans. On Power Systems, Vol.18, No.4, Nov.2003, pp 1359-1365.

[14] X.P.Zhang, "Robust Modeling of the Interline Power Flow Controller and the Generalized Unified Power Flow Controller with Small Impedances in Power Flow Analysis", Electrical Engineering, Vol.89 no.1. October 2006, p.gno:1-9.

[15] B. Karthik, I. Alagarasan, S. Chandrasekhar, "Optimal Location of Interline Power Flow Controller For Controlling Multi-Transmission Line: A New integrated Technique", Research Article Electrical Electronics Engg, Higher Education Press and Springer-2012, PP 447-458.

[16] Yang Ye, Mehrdad Kazerani, "Power flow control schemes for series-connected FACTS controllers", Electric Power Systems Research, 76 (2006) 824-831.

[17] Akanksha Mishra, Venkata Nagesh Kumar Gundavarapu, "Contingency management of power system with Interline Power Flow Controller using Real Power Performance Index and Line Stability Index", Ain Shams Engineering Journal, Volume 7, Issue 1, March 2016, Pages 209-222.

[18] An Improved Steady-State Model of an Interline Power Flow Controller for the Multi-Transmission System, International Journal of Grid and Distributed Computing, Vol.9, No.5, May 2016, pp.13-24.

[19] Hadi Sadat, "Power System Analysis" Tata McGrawHill Edition 2001 